\title{
Del texto a los contextos
}

\author{
Jorge Alcázar
}

Este artículo bosqueja, con pinceladas amplias, el cambio de paradigmas conceptuales en el campo de la teoría literaria durante el siglo xx. Se muestra cómo las teorías esencialistas, como el primer formalismo ruso o el new criticism norteamericano, buscaban modelos explicativos a través de conceptos como la literariedad o la ironía. Se revisa el impacto de la lingüística en el quehacer teórico de los estudios literarios, en especial en el estructuralismo francés. Finalmente se describe cómo otros enfoques —entre los que se encuentran el dialogismo bajtiniano, el neohistoricismo y la estética de la recepción - pusieron en crisis esas aproximaciones al fenómeno literario, a la vez que ampliaron los modos de comprensión de los textos de creación.

PalABRAS ClaVe: teoría literaria, formalismo ruso, new criticism, dialogismo bajtiniano, estética de la recepción.

This article traces, by means of wide strokes, the shift of conceptual paradigms in twentieth century literary theory. An attempt is made to show how essentialist approaches, such as early Russian formalism and American new criticism, sought to offer explanatory models through concepts like literariness or irony. We also look at the theoretical impact generated by linguistics in the domain of literary studies, especially in French structuralism. The last part of the essay concentrates on alternative models - like Bakhtinian dialogism, new historicism and reception theory, among others- which widened the possibilities to conceive and understand how imaginative literature works. 

Jorge Alcázar

Facultad de Filosofía y Letras, UNAM

\section{Del texto a los contextos}

$I$

En un gesto de excesiva generalización, se puede afirmar que los estudios literarios -en sus versiones más sofisticadas y prominentes - estuvieron, durante buena parte del siglo pasado, dominados por un impulso que buscaba la esencia de lo literario. Desde diferentes perspectivas y postulados teóricos se trató de encarar, por lo general desde un punto de vista formal, aquello que hacía que un objeto verbal - ya fuera un poema o una novela - se considerara una obra artística. Las respuestas que se presentaron, en el tapete del debate conceptual, apelaban a modelos que realzaban la estructura y la organicidad de las obras literarias.

Los representantes de la primera etapa del formalismo ruso, imbuidos del ejemplo de Saussure (quien rechazó la herencia histórico-positivista del siglo XIX), trataron de fundar una ciencia de la literatura que se desentendiera de lo que rodeaba a la obra y se concentrara en lo que había en ella. Así, Roman Jakobson en 1921, no sin cierto dejo de desdeño, afirmaba que los historiadores de la literatura eran como: 
[...] la policía que, en el transcurso del arresto de un individuo, se apodera al azar de todo lo que se encuentra en su casa e, inclusive, de las personas que pasan por la calle. De manera semejante, los historiadores de la literatura echan mano de todo: vida personal, psicología, política, filosofía. En lugar de una ciencia de la literatura, se crea un conglomerado de disciplinas domésticas, y se olvida que a esos objetos les corresponden sus propias ciencias: la historia de la filosofía, la historia de la cultura, la psicología, etcétera (apud Pascual Buxó, Introducción, 17).

Por lo tanto, para Jakobson, como para los otros formalistas, si los estudios literarios querían alcanzar el estatuto de ciencia debían abocarse al estudio del "lenguaje en su función estética", y considerar al "procedimiento" como su único protagonista; de tal suerte que, en esta primera fase de reflexión, se vio a la obra como la suma de sus procedimientos. Aquí la pregunta capital giró en torno al concepto de "literariedad", y las respuestas que se propusieron fueron de índole relacional. Así Viktor Shklovsky, en La teoría de la prosa (1925), decía: "La obra literaria es forma pura, no es una cosa, ni es material, sino la relación del material" (apud O'Toole, Shukman, "A Contextualist Glossary", 19). Debemos tener presente que, dentro de los esquemas formalistas, material significaba la lengua, la materia verbal y sus implicaciones respecto al ritmo, metro, tono; y estos elementos debían examinarse respecto a la totalidad de la obra.

Con el correr de los años, se ampliaría el espectro de preocupaciones del formalismo ruso, y habría lugar — gracias a la aportación de Tinianov- para el concepto de evolución literaria, la función cambiante de la obra y sus procedimientos y la relación entre literatura y las series no-literarias. Sin embargo, esta nueva orientación del proyecto teórico de los formalistas no rendiría frutos inmediatos, ya que el movimiento se vio trunco y sus representantes se dispersaron, al final de los años veinte, ante la creciente amenaza del aparato cultural estalinista. 
El legado de este programa teórico no tendría eco en Occidente sino hasta los años sesenta. Se pueden encontrar referencias con anterioridad. Y así resulta algo sorprendente que Alfonso Reyes tenga noticia de ellos allá por 1940 (Apuntes, 379-380), lo que no significa de ninguna manera que los conociera de primera mano. Se les menciona en el manual de Wellek y Warren, Theory of Literature (1949), pero es hasta mediados de los cincuenta que encontramos, en el estudio de Victor Erlich, Russian Formalism: History and Doctrine, el primer bosquejo general de sus ideas y su aportación al desarrollo de la teoría literaria en nuestro siglo. Y sería sólo hasta la década siguiente, con la aparición de varias antologías —en inglés, francés, alemán - cuando se les comienza a leer y a conocer realmente. Más adelante veremos de qué manera las ideas formalistas influyeron en el estructuralismo francés y la teoría de la recepción.

\section{II}

Otra corriente que se orientó hacia el estudio del aspecto formal fue el new criticism norteamericano. De origen sureño y anquilosado individualismo, carente de la capacidad teórica del formalismo ruso, logró — no obstante estas limitaciones- desempeñar un papel predominante en la cultura estadounidense por más de dos décadas, principalmente en el campo de la enseñanza de la literatura. Herederos del autotelismo de T. S. Eliot y del "close reading" que se practicaba en la Universidad de Cambridge, los new critics, en especial Cleanth Brooks y Robert Penn Warren, apuntaron sus baterías a la elaboración de obras didácticas: antologías comentadas que buscaban conducir al alumno a la apreciación correcta de la literatura y que pretendían de paso inculcar una suerte de humanismo conservador. 
La manera en que los new critics trataron de explicar lo literario fue a través de su concepción tensional de la poesía, misma que heredaron del pensamiento romántico de Coleridge y de las ideas críticas de I. A. Richards. Según esta concepción, en un poema encontramos impulsos disímbolos que están en una suerte de equilibrio; a esto, dentro de su vocabulario crítico, lo denominaron indistintamente "paradoja", "tensión" o "ironía". A pesar de enarbolar una bandera "formalista" (Brooks, por ejemplo, publicó en 1951 el decálogo del crítico formalista), un concepto como el de paradoja o tensión no es una categoría descriptible e identificable en un texto, sino que presupone que el poema es la arena donde se dirime algún tipo de conflicto.

Más interesante como hipótesis explicativa es la teoría icónica de W. K. Wimsatt. Siguiendo los planteamientos semióticos de Charles Morris, Wimsatt argumentaba en The Verbal Icon (1954) que el fenómeno de la iconicidad — es decir, la capacidad imitativa del lenguaje que corporiza en sí mismo aquello que representa — hacía más denso el medio verbal de la poesía. $\mathrm{Al}$ intensificar la verbalidad del texto, éste adquiría una solidez icónica semejante a la materialidad plástica de una estatua o una vasija. ${ }^{1}$ Planteamiento similar a los de Jakobson en "¿Qué es la poesía?" (1934). Sin embargo, la teoría icónica no tendría seguidores en los Estados Unidos, y el propio Wimsatt —en sus últimos años - volvería a la concepción tensional. ${ }^{2} \mathrm{Al}$ final de la década de los sesenta, Yuri Lotman hablaría del lenguaje poético en términos de iconicidad y semantización de unidades mínimas, pero llegaría a ello vía Jakobson y la semiótica pierciana.

Al afirmar la organicidad de los textos literarios y privilegiar los enfoques intrínsecos que buscaban el sentido de los

1 "[P]oetry by thickening the medium increases the disparity between itself and its referents" (Wimsett, The Verbal Icon, 217).

${ }^{2}$ Para un tratamiento más detallado, véase Alcázar, "La nueva crítica norteamericana". 
mismos, los new critics entraron en pugna con otras tendencias que todavía defendían los métodos histórico-biográficos. Una de las escuelas que hizo algo de mella al "monismo crítico" de Brooks y compañía fue la asentada en la Universidad de Chicago, que seguía una línea neoaristotélica en relación con los géneros literarios, y cuyas figuras principales fueron R. S. Crane y, más tarde, Wayne Booth. Otra tendencia que se hizo sentir fue la que, inspirada en las ideas de Jung y Frye, se orientaba hacia la interpretación mítica y arquetípica, sin descuidar el trasfondo histórico de las obras, como lo testifican los escritos de Richard Chase.

Para los años sesenta el "new criticism" parecía en declive; y así, en el prefacio a la segunda edición de su gozoso libro Love and Death in the American Novel (1966), Leslie Fiedler afirmaba: "El año 1960 no ha quedado muy atrás; pero ciertos tipos de crítica que todavía se practicaban y se admiraban entonces - los últimos ejemplos de una nueva tradición de lo refinado, con su acento en el análisis textual, su desprecio por las ideas generales y su temor a la cultura popular - ahora nos parecen remotos y poco pertinentes". Y añadía, argumentando en favor de un enfoque que apelara a los diferentes contextos de la obra, ya fueran éstos históricos, antropológicos o genéricos: "El crítico contextual solamente quiere ubicar la obra de arte, apuntar hacia el lugar donde sus círculos contextuales se entrecruzan, el lugar en que la obra existe en toda su ambigüedad y plenitud" (pp. 8, 10) . Y así Fiedler echa mano tanto de la historia y la migración de las formas literarias (el asentamiento de la novela gótica en Norteamérica), como de los influjos tutelares más disímbolos, entresacados de los escritos de C. S. Lewis, Karl Marx, Sigmund Freud, C. G. Jung, D. H. Lawrence. Antes que se acuñara el concepto de imaginario social, Fiedler ya habla de las "fantasías comunales" que pueblan la cultura y la literatura norteamericana. Entre ellas se hallan la incapacidad de los novelistas para crear retratos convincentes de amor 
heterosexual entre adultos, y su consecuente obsesión por la muerte, el incesto y la homosexualidad inocente o latente, que encontramos en muchos personajes de la narrativa estadounidense. Al igual que varias de las figuras de los años sesenta, Fiedler no hizo escuela: su estilo iconoclasta, antiacadémico - que combinaba lo coloquial y la topicalidad de lo inmediato- no le permitió tener seguidores. Además, las modas de la crítica apuntaban hacia otra parte.

\section{III}

Con la llegada del estructuralismo, encontramos el surgimiento de un nuevo paradigma como modelo de las ciencias humanas: el linguíístico. Ya desde los años cuarenta, cuando Claude LéviStrauss y Jakobson coincidieron en la Escuela Libre de Altos Estudios de Nueva York, el antropólogo francés vislumbró lo que debería ser su disciplina. Al asistir a los cursos de Jakobson sobre lingüística y fonología, Lévi-Strauss intuyó que la antropología debería seguir el ejemplo de la linguiística: al considerar los fenómenos que estudiaba como si fueran sistemas autónomos. Fenómenos como el del parentesco, el tabú del incesto o los mitos propios de una cultura, podrían ser vistos como sistemas cuyos elementos tendrían marcas funcionales semejantes a las diferencias y oposiciones que encontramos en las lenguas naturales. Asimismo se podría dar cuenta de ellos - como se hace con los rasgos distintivos en el campo de la fonología - asignándoles una posición dentro de una red de oposiciones binarias.

En los años sesenta, se trató de incorporar este principio metodológico tanto a los estudios literarios como a otras disciplinas. Se intentó dar cuenta de una obra apelando a los criterios de clasificación y segmentación que encontramos en los niveles clásicos de descripción lingüística. Tal es el caso del manual de Tzvetan Todorov Poética en la serie ¿Qué es el estructura- 
lismo?, donde se proponen tres niveles de análisis literario: el verbal, el sintáctico y el semántico. Gestos semejantes encontramos en el primer Barthes de los nudos y las catálisis de esa época, para quien la linguística constituye el "modelo fundador del análisis estructural del relato".

Otro ejemplo de préstamos conceptuales de origen lingüístico se puede ver en la dicotomía narratológica historia/discurso. Aquí nos encontramos ante una transposición analógica que distorsiona el sentido y la cobertura original que Emile Benveniste le asigna a esta pareja de términos en su modelo de la enunciación. Recordemos que el lingüista francés alude con esta dicotomía a los dos polos postulables que puedan remitirnos o no al sujeto que enuncia en cualquier manifestación lingüística: un grado cero en la historia (¿quién narra o desde dónde se enuncia un texto histórico?) en contraste con las marcas de subjetividad (deícticos, pronombres personales, etc.) en el discurso. En el relato histórico nadie parece hablar: sólo hay la sucesión de acontecimientos que parecen narrarse a sí mismos. En cambio lo que han hecho los narratólogos estructuralistas, como Todorov o Genette, es acercar estos términos a la pareja de conceptos formalistas de fabula y sjuzet. Según la formulación canónica de Tomashevski:

Son los formalistas rusos los primeros que aislaron estas dos nociones con el nombre de fábula ("lo que efectivamente ocurrió") y tema ("la forma en que el lector toma conocimiento de ello") (apud Todorov, "Las categorías", 161).

\section{IV}

Si atrás de los modelos formalista y estructuralista se encontraban los postulados de Ferdinand de Saussure, ya desde finales de los años veinte una figura poco conocida en ese entonces había cuestionado tales postulados. Me refiero a Mijaíl Bajtín 
y a su grupo de trabajo que incluía a figuras como Valentin $\mathrm{N}$. Voloshinov y P. N. Medvedev.

La teoría de Bajtín, a diferencia de la teoría abstracta saussureana preocupada por los principios sistémicos, es un modelo discursivo que asume que toda actividad verbal presupone una posición dialógica. Tratemos de aclarar esta idea. Saussure parte del concepto de signo, en tanto principio semiótico. Bajtín parte de la situación mínima comunicativa del diálogo cara a cara, en donde hay intercambio de roles enunciativos. Esto implica - a diferencia del reconocimiento pasivo del signo saussureano, que es estable y unívoco (significante + significado)una participación activa en el acto mismo de la comunicación. La situación dialógica presupone un antes y un después, el oír y contestar, el anticipar y reaccionar, el escuchar y rebatir, la gesticulación e inclusive la burla.

El dialogismo no sólo permea el acto de la comunicación, sino hasta el concepto mismo de signo. Para Saussure, el signo linguístico es como el anverso y el reverso de una hoja de papel (Curso, 191-206). Esta analogía le sirve para señalar la unión indisoluble del significante y el significado dentro del juego de oposiciones de la lengua como sistema. Es más, los diagramas escolares a que recurre sugieren que una vez fijada la imagen mental del signo en la cabeza del hablante, permanecerá allí de por vida. Para Bajtín, por el contrario, el signo es dinámico y mutable, y esta variabilidad es resultado de los contextos por los que ha pasado. A diferencia del gesto primigenio saussureano que parece insinuar que, independientemente de la arbitrariedad del signo, una vez que se designan las cosas quedan nombradas para siempre, o por lo menos por la duración de un corte sincrónico, Bajtín nos propone que las palabras que enunciamos están cargadas, habitadas o incluso contaminadas por los contextos por los que han pasado o por las personas que las han usado.

Construimos nuestros enunciados bajo la conciencia y el marco perceptual de hacia quién van dirigidos, es decir, de 
nuestro posible destinatario, quien tal vez no comparta nuestra visión del mundo y que seguramente tendrá un horizonte ideológico distinto al nuestro. De estas posiciones disímbolas $\mathrm{y}$, a veces, asimétricas nacen las diferencias heteroglóticas que, en algún momento del devenir histórico, se convertirán en fórmulas de saludo y convenciones de conversación (el repertorio de "pequeños géneros cotidianos"), códigos de urbanidad, estilos epistolares, jergas profesionales, formulismos burocráticos, lenguajes generacionales, modas extranjerizantes, tácticas de cortejo y enamoramiento, la temática de chistes y bromas, el saber popular, la voz del poder oficial, la formación de los estilos literarios, pudiéndose llegar incluso a "la palabra ajena" de los pueblos dominantes y el subsecuente adoctrinamiento de sus cultos religiosos.

Los actos enunciativos que conforman y definen a todo individuo están cruzados por esta multiplicidad de lenguajes posibles, que Bajtín denomina estratificación discursiva o heteroglosia. Paradójicamente, es gracias a la conciencia o a la presencia del otro en nuestro lenguaje que podemos consolidar nuestra propia identidad. Por lo que desde esta perspectiva, tanto la postura del subjetivismo idealista (el acto volitivo, creador, individualista, característico de las estilísticas psicologizantes, que bajo las premisas bajtinianas sería una contradicción lógica) como la del objetivismo abstracto (un sistema linguiístico internalizado que condiciona y constriñe la libertad del hablante) carecen del basamento conceptual adecuado para dar cuenta del rasgo que distingue realmente a los seres humanos: el uso y el acto de la palabra (Voloshinov, Marxismo, 73-94). Como alternativa al reduccionismo de la lingüística saussureana estructural, interesada tan sólo en el funcionamiento del sistema, Bajtín propone una translingüística que empalmaría parcialmente con los campos de estudio de la sociolingüística moderna, la pragmática del discurso y una estilística histórica. 
En lo que concierne al campo de los estudios literarios, Bajtín estaba a favor de una poética histórica. Buscaba explicaciones que dieran cuenta de la evolución y transformación de los géneros literarios, en especial de la prosa narrativa. Se interesaba por deslindar el modo en que los géneros simples se incorporan a formas secundarias más complejas como el drama y la novela. "En el proceso de su formación estos géneros absorben y reelaboran diversos géneros primarios (simples) constituidos en la comunicación discursiva inmediata" (Bajtín, Estética, 250). Al volverse parte de los géneros secundarios, las formas simples pierden algo de su relación inmediata con la realidad. De esta manera, la carta o el diálogo ingresan al enunciado total de la obra, "como acontecimiento artístico y no como suceso de la vida cotidiana".

Así postuló que en la prehistoria del género novelístico participaron en su conformación tanto el diálogo socrático como la sátira menipea. El diálogo socrático, que tiene sus raíces en el folklore y el carnaval, nos presenta el problema de la verdad y los caminos que seguimos para acercarnos a ella. En esta búsqueda de la verdad coincide con la sátira menipea, ya que ésta — por medio de la aventura y "la fantasía más audaz e irrefrenable"- crea "situaciones excepcionales para provocar y poner a prueba la idea filosófica, la palabra, y la verdad plasmada en la imagen del sabio buscador de esta verdad" (Bajtín, Problemas, 161). A diferencia del "realismo formal" de Ian Watt, orientado hacia modos verosimilizantes de representación con los que este crítico anglosajón trata de explicar el surgimiento de la novela en la Inglaterra del siglo XVIII, el marco conceptual de Bajtín sería mucho más amplio. Para él los límites temporales de la novela incluirían, además de la sátira menipea, la novela bizantina, los romances artúricos caballerescos, los relatos folclóricos y aun los hagiográficos, habiendo incluso espacio para 
novelas escritas en verso como Eugenio Onegin o el Don Juan de Byron. A final de cuentas lo que importaría es la capacidad del autor para escuchar y recrear en sus obras las hebras y los cruces dialógicos de su momento, y la novela se convertiría potencialmente en el máximo registro de las voces sociales de una época.

Bajtín hace patente su postura de esta manera:

Pero para que estos factores de contenido formen parte de nueva forma de visión artística, para que generen una nueva estructura de la novela polifónica, fue necesaria una larga preparación de tradiciones estéticas generales y literarias. Las nuevas formas de la visión artística se preparan lentamente, por siglos; una época tan sólo crea las condiciones óptimas para la madurez definitiva y para la realización de la nueva forma. La tarea de la poética histórica es descubrir este proceso de fundamentación artística de la novela polifónica (Bajtín, Problemas, 59-60).

\section{$V I$}

Otras tendencias han ampliado el espectro de los estudios literarios, introduciendo a veces elementos y variables que solían quedar en un plano secundario. En primer lugar, hay que mencionar una revaloración de la dimensión histórica desde diferentes perspectivas. Ya sea que se conceptualicen como neohistoricismos que recontextualizan el pasado, y que en varios casos siguen la impronta de Michel Foucault. Para el pensador francés lo que hay que hacer con el discurso es insertarlo en el juego de su instancia, en su irrupción como acontecimiento, es decir, "en esa coyuntura en que aparece y en esa dispersión temporal que le permita ser repetido, sabido, olvidado, transformado, borrado hasta en su menor rastro, sepultado, muy lejos de toda mirada, en el polvo de los libros" (Foucault, Arqueología, 41). Esto es lo que hace gente como Stephen Greenblatt al 
allegarse textos y panfletos que circulaban en una época (como la isabelina), tratando de proyectar una mirada novedosa sobre las obras de un autor como podría ser Shakespeare.

Otra postura que busca reconstruir los contextos del pasado es el punto de vista propuesto por el feminismo, ya sea intentando rescribir la historia literaria desde la perspectiva de las autoras mujeres o asumiendo que hay una sensibilidad propia que las caracteriza y las distingue de sus pares masculinos. Esta manera de ver las cosas la encontramos en estudios como The True Story of the Novel (1997) de Margaret Anne Doody o en libros ya clásicos como The Madwoman in the Attic (1979) de Sandra Gilbert y Susan Gubar.

También debe mencionarse los planteamientos de la estética de la recepción, representada por Wolfgang Iser, con sus estudios sobre el papel del lector, y Hans Robert Jauss, quien exploró las cuestiones relacionadas con la historicidad de la lectura. En un famoso ensayo, "La historia de la literatura como provocación de la ciencia literaria”, Jauss introduce la noción de diferencia hermenéutica, es decir, la distancia histórica que media entre la comprensión de ayer y la de hoy. Valiéndose de Gadamer y a su vez cuestionando su clasicismo y creencia en la posible fusión de horizontes conceptuales, Jauss asume que hay una historicidad de la lectura, en la que el receptor debe reconocer una tensión entre el texto (sea de cualquier época) y su actualidad. Algo de ello ya estaba vislumbrado por Tinianov con el concepto formalista de evolución literaria, cuando hablaba de la mutación de las formas literarias, es decir, la renovación y mutación de procedimientos expresivos, pero no incluía la posición histórica del observador actual. Esto exige, a su vez, tomar en cuenta cómo cambian en el tiempo los horizontes de los posibles receptores ya que lo que es ilegible en un momento - el tipo de resistencias que la nueva obra tiene que enfrentar con su primer público-, con el correr del tiempo puede ser altamente asimilable. Así el proceso legal contra Ma- 
dame Bovary, además de reflejar un juicio moral, muestra que los primeros lectores no estaban preparados para decodificar una forma de narración impersonal a la que aspirarían muchos novelistas del siglo xx; otro ejemplo sería cómo la oscura lírica de Mallarmé prepara el terreno para la revaloración, por parte de las vanguardias, de la poesía barroca, poco apreciada y casi olvidada (Jauss, La literatura como provocación, 181-211).

Tal visión del fenómeno literario tiene como corolario que lo nuevo como categoría estética e histórica afecta nuestra comprensión de aquello que lo ha antecedido. Empero si reconsideramos esta idea por un momento, nos daremos cuenta que ya había sido anticipada por los propios escritores. Cuando T. S. Eliot imagina, en su famoso ensayo "Tradition and the Individual Talent", la literatura europea - de Homero al presente- como un orden ideal y simultáneo cuyos contornos se reacomodan con el advenimiento de aquellas obras que son realmente originales, ¿no está planteando algo parecido al presuponer que el presente modifica nuestra comprensión del pasado? Algo por el estilo parece estar diciendo Bajtín cuando, al considerar la obra de Dostoievski en relación con la herencia clásica de la sátira menipea, afirma que existe una memoria objetiva del género literario que pervive y que la hace diferente de la memoria subjetiva y limitada del autor (Bajtín, Problemas, 171). O ¿no encontraríamos un caso igualmente paradojal cuando Borges postula que un escritor crea a sus propios precursores aun sin haberlos leído, como le sucede a Kafka en relación con el amanuense inventado por Melville? Borges nos dice, en el prólogo a su traducción del relato: "yo observaría que la obra de Kafka proyecta sobre Bartleby una curiosa luz ulterior. Bartleby define ya un género que hacia 1919 reinventaría y profundizaría Franz Kafka: el de las fantasías de la conducta y del sentimiento o, como ahora malamente se dice, psicológicas" (Borges, Prólogos, 117). Comentario que amplía en su ensayo sobre Hawthorne: 
La circunstancia, la extraña circunstancia, de percibir en un cuento de Hawthorne, redactado a principios del siglo XIX, el sabor mismo de los cuentos de Kafka que trabajó a principios del siglo Xx, no debe hacernos olvidar que el sabor de Kafka ha sido creado, ha sido determinado, por Kafka. Wakefield prefigura a Franz Kafka, pero éste modifica, y afina, la lectura de Wakefield. La deuda es mutua; un gran escritor crea a sus precursores. Los crea y de algún modo los justifica. Así ¿qué sería de Marlowe sin Shakespeare? (Borges, Otras disquisiciones, 84).

Ahora, en los albores del siglo xxI, pareciera que con la apertura del canon cualquier texto (ya sea la autobiografía de un esclavo norteamericano, el diario de una ama de casa, el relato de una minoría étnica o un manifiesto político) puede ser considerado como objeto de estudio literario; o como dice la canción de Cole Porter: "Anything goes". El defensor a ultranza del canon occidental, Harold Bloom, nos propuso hace más de diez años regresar al valor estético de las obras, sopesando la sublimidad textual y la extrañeza provocada por las mismas, como metro de referencia. Él se ha quejado, una y otra vez, de la ascendencia que ha tenido en las esferas universitarias lo que él denomina como la "escuela del resentimiento". Con este término trata de englobar seis ramas teóricas recientes: el neohistoricismo, el materialismo cultural, el feminismo, la deconstrucción, el psicoanálisis lacaniano y los enfoques semióticos. Según Bloom, estas tendencias críticas han dado al traste con la lectura y la enseñanza de la literatura. La supuesta apertura del canon y su ampliación han significado, según él, su aniquilación, ya que el logro artístico ha quedado en un plano inferior de importancia (Bloom, The Western Canon, 517-528). Como contraparte, Iris Zavala apuntaba en una reseña: "El crítico del establishment académico nos invita a conjurar el fantasma del multiculturalismo y las otras plagas que corren por Occidente, invocando un concepto tradicional de lectura" (Zavala, "El canon y Harold Bloom", 50). 
Yo creo que ahora nos encontramos ante una paradoja educativa. Por un lado, hemos podido formar estudiantes más diestros para manejar argumentos y conceptos, capaces de probar, casi de manera sofística, cualquier punto que se propongan. Por el otro, corroboramos continuamente que hay elementos textuales o estructurales, alusiones literarias o culturales o mucho de lo que se puede codificar en una obra artística que permanece inadvertido para ellos. Solamente el futuro nos podrá decir si hemos avanzado realmente o retrocedido sin percatarnos de ello.

\section{REFERENCIAS}

AlcázAr, Jorge, "La nueva crítica norteamericana", Acta Poetica, 8, 1987, 135-163.

Bajtín, M. M., Estética de la creación verbal, trad. Tatiana Bubnova, México, Siglo XXI, 1982.

_- Problemas de la poética de Dostoievski, trad. Tatiana Bubnova, México, Fondo de Cultura Económica, 1986.

Bloom, Harold, The Western Canon, New York, Harcourt Brace, 1994.

Borges, Jorge Luis, Otras inquisiciones, Buenos Aires, Emecé, 1960. —, Prólogos, Buenos Aires, Torres Agüero, 1975.

Fiedler, Leslie A., Love and Death in the American Novel, New York, Delta, 1966.

Foucault, Michel, La arqueología del saber, trad. Aurelio Garzón del Camino, México, Siglo XXI, 1970.

JAUss, Hans Robert, La literatura como provocación, trad. Juan Godo Costa, Barcelona, Península, 1976.

O'Toole, L. M. y Ann Shukman, "A Contextualist Glossary of Formalist Terminology", Russian Poetics in Translation, 4, 1977, 13-48.

Pascual Buxó, José, Introducción a la poética de Roman Jakobson, México, Universidad Nacional Autónoma de México, 1978.

Reyes, Alfonso, Apuntes sobre la ciencia de la literatura, en Obras completas, vol. XIV, México, Fondo de Cultura Económica, 1962. 
Saussure, Ferdinand de, Curso de lingüística general, trad. Amado Alonso, Buenos Aires, Losada, 1945.

Todorov, Tzvetan, "Las categorías del relato literario", en Roland Barthes et al., Análisis estructural del relato, México, Premiá, 1982, 159-194.

Voloshinov, Valentin N., El marxismo y la filosofía del lenguaje, trad. Tatiana Bubnova, Madrid, Alianza, 1992.

WimsatT, W. K., The Verbal Icon, Lexington, University of Kentucky Press, 1954.

Zavala, Iris M., "El canon y Harold Bloom", Quimera, 145, marzo 1996, 49-54. 